\title{
Transcriptional profiling of Saccharomyces cerevisiae exposed to propolis
}

Patrícia Alves de Castro ${ }^{1}$, Marcela Savoldi ${ }^{1}$, Diego Bonatto², Iran Malavazi ${ }^{3}$, Maria Helena S Goldman", Andresa A Berretta ${ }^{1,5}$ and Gustavo Henrique Goldman ${ }^{1,6^{*}}$

\begin{abstract}
Background: Propolis is a natural product of plant resins collected by honeybees (Apis mellifera) from various plant sources. Our previous studies indicated that propolis sensitivity is dependent on the mitochondrial function and that vacuolar acidification and autophagy are important for yeast cell death caused by propolis. Here, we extended our understanding of propolis-mediated cell death in the yeast Saccharomyces cerevisiae by applying systems biology tools to analyze the transcriptional profiling of cells exposed to propolis.
\end{abstract}

Methods: We have used transcriptional profiling of S. cerevisiae exposed to propolis. We validated our findings by using real-time PCR of selected genes. Systems biology tools (physical protein-protein interaction [PPPI] network) were applied to analyse the propolis-induced transcriptional bevavior, aiming to identify which pathways are modulated by propolis in S. cerevisiae and potentially influencing cell death.

Results: We were able to observe 1,339 genes modulated in at least one time point when compared to the reference time (propolis untreated samples) (t-test, $p$-value 0.01 ). Enrichment analysis performed by Gene Ontology (GO) Term finder tool showed enrichment for several biological categories among the genes up-regulated in the microarray hybridization such as transport and transmembrane transport and response to stress. Real-time RT-PCR analysis of selected genes showed by our microarray hybridization approach was capable of providing information about $\mathrm{S}$. cerevisiae gene expression modulation with a considerably high level of confidence. Finally, a physical protein-protein (PPPI) network design and global topological analysis stressed the importance of these pathways in response of $\mathrm{S}$. cerevisiae to propolis and were correlated with the transcriptional data obtained thorough the microarray analysis.

Conclusions: In summary, our data indicate that propolis is largely affecting several pathways in the eukaryotic cell. However, the most prominent pathways are related to oxidative stress, mitochondrial electron transport chain, vacuolar acidification, regulation of macroautophagy associated with protein target to vacuole, cellular response to starvation, and negative regulation of transcription from RNA polymerase II promoter. Our work emphasizes again the importance of $\mathrm{S}$. cerevisiae as a model system to understand at molecular level the mechanism whereby propolis causes cell death in this organism at the concentration herein tested. Our study is the first one that investigates systematically by using functional genomics how propolis influences and modulates the mRNA abundance of an organism and may stimulate further work on the propolis-mediated cell death mechanisms in fungi.

\footnotetext{
* Correspondence: ggoldman@usp.br

${ }^{1}$ Faculdade de Ciências Farmacêuticas de Ribeirão, Preto Universidade de São Paulo, São Paulo, Brazil

${ }^{6}$ Laboratório Nacional de Ciência e Tecnologia do Bioetanol - CTBE, Caixa

Postal 6170, Campinas, São Paulo 13083-970, Brazil

Full list of author information is available at the end of the article
} 


\section{Background}

Propolis is a natural product of plant resins collected by honeybees (Apis mellifera) from various plant sources. It is used by the bees to seal holes in their honeycombs and protect the hive entrance [1-3]. Propolis has been used in folk medicine for centuries. Its chemical composition is quite complex since more than 300 compounds, such as polyphenols, phenolic aldehydes, sequiterpene quinines, coumarins, amino acids, steroids, and inorganic compounds, have been identified in propolis samples. Propolis has cytotoxic [4], anti-herpes virus [5], antitumor [6], radical scavenging [7], antimicrobial $[8,9]$, antiprotozoan [10], and anti-HIV [11] activity and suppressive effects of dioxin toxicity [9]. More recently, evidence has shown that propolis can be used to treat Candida fungal infections [12-16].

Recently, we applied the power of Saccharomyces cerevisiae as a model organism for studies of genetics, cell biology, and genomics to determine how propolis affects eukaryotic cells at the cellular level [17]. Propolis is able to induce an apoptosis cell death response; however, increased exposure to propolis provides a corresponding increase in the necrosis response. We showed that cytochrome $c$ but not endonuclease G (Nuclp) is involved in propolis-mediated cell death in S. cerevisiae. We also observed that the metacaspase YCA1 gene is important for propolis-mediated cell death. We screened the full collection of about 4,800 haploid S. cerevisiae nonessential deletion mutants for propolis sensitivity, and we were able to identify 138 deletion strains that have different degrees of propolis sensitivity compared to the corresponding wild-type strains. Our studies indicated that propolis sensitivity is dependent on the mitochondrial function and that vacuolar acidification and autophagy are important for yeast cell death caused by propolis. Here, we extended our understanding of propolis-mediated cell death in the yeast Saccharomyces cerevisiae by applying systems biology tools to analyze the transcriptional profiling of cells exposed to propolis.

\section{Methods}

\section{Propolis tandardized extract}

Propolis Standardized Extract - (EPP-AF $\left.{ }^{\circledR}\right)$ (Batch 010/ 08) were industrially produced and kindly provided by Apis Flora Company (RibeirãoPreto/SP - Brazil). The extract was standardized using a propolis blend composed by raw material obtained from several sites of Brazil (Patent number PI 0405483-0, published in Revista de Propriedade Industrial n. 1778 from 01/02/2005). Propolis (blend of raw material) was kept in a freezer for $12 \mathrm{~h}$, ground to a fine powder in a blender. It was then extracted using hydroalcoolic solution (7:3), with dinamic maceration, during 72 hours in ambient conditions $\left(25^{\circ} \pm 5^{\circ} \mathrm{C}\right)$, followed by percolation process $(1 \mathrm{~L} /$ min.) and finally by a filtration process using in the first step the propolis biomass like a filter and secondly a 220 mesh stainless steel industrial line filter. Propolis extract obtained presents $11 \% \mathrm{w} / \mathrm{v}$ of dry matter and chemical composition standardized qualitatively and quantitatively by RP-HPLC (C18 Shim-pack, CLC-ODS (M), $25 \mathrm{~cm} \mathrm{x}$ 4,6 column -with gradient elution with methanol and acidic water $\mathrm{pH}=2,7$, plotted at $275 \mathrm{~nm}$ ) into compounds: caffeic, $p$-coumaric and cinnamic acids, aromadendrin, isosakuranetin and artepillin $\mathrm{C}$.

\section{Yeast strain, media and culture methods}

The assays were carried out with $S$. cerevisiae yeast strain BY4742 (MATo; his $3 \Delta 1$; leu2 $\Delta 0$; lys $2 \Delta 0$; ura $3 \Delta 0$ ) [18]. The culture medium used was complete medium YPD $(2 \% \mathrm{w} / \mathrm{v}$ glucose, $1 \% \mathrm{w} / \mathrm{v}$ yeast extract, $2 \% \mathrm{w} / \mathrm{v}$ peptone). For the microarray assay, the yeast cells were grown for 9 hours (mid-exponential phase) in $50 \mathrm{~mL}$ of liquid YPD at $30^{\circ} \mathrm{C}$ with mechanical shaking (200rpm). After this, the cells $\left(\sim 2 \times 10^{7}\right.$ cells $\left.\mathrm{ml}^{-1}\right)$ were exposed to propolis $0.125 \%$ for 5 or 10 minutes. The control for the experiment using propolis $0.125 \%$ as a treatment has $0.68 \%$ ethanol. Two independent experiments were performed to each array using two different biological samples and dye swap analysis. Cell viability was determined by plating appropriate cell concentrations and counting the number of colonies in comparison to propolisuntreated controls.

\section{RNA isolation and real-time PCR}

For total RNA isolation, the yeast cells were disrupted by vortexing with glass beads and total RNA was extracted with Trizol reagent (Invitrogen, USA). Ten micrograms of RNA from each treatment were then fractionated in $2.2 \mathrm{M}$ formaldehyde, $1.2 \% \mathrm{w} / \mathrm{v}$ agarose gel, stained with ethidium bromide, and then visualized with UV-light. The presence of intact $25 \mathrm{~S}$ and $18 \mathrm{~S}$ ribosomal RNA bands was used as a criterion to assess the integrity of the RNA. RNAse free DNAse treatment was carried out as previously described [19]. After this, the total RNA was purification by RNeasy ${ }^{\circledR}$ Mini Kit (Qiagen) and the purified samples were measured in the NanoDrop ${ }^{\circledR} 2000$ (Thermo Scientific).

\section{Microarray hybridization}

For gene expression analysis commercially-available Agilent whole genome S. cerevisiae microarray [Yeast (V2) Gene Expression Microarray, 8x15K] was used. The microarray slides contain 15,208 probes for S.cerevisiae (BY4742 strain). The RNA samples obtained under the conditions above described were subjected to cRNA fluorescent labeling. cRNA labeling was performed according to the standard protocol described by Agilient using Two-Color Microarray-Based Gene Expression 
Analysis (Agilent Technologies, USA). Briefly, for cRNA synthesis and labeling $5 \mu \mathrm{g}$ of total RNA were used. After labeling, $300 \mathrm{ng}$ of Cy3 and Cy5-labelled cRNAs (specific activity > $8.0 \mathrm{pmol} \mathrm{Cy} 3-\mathrm{Cy} 5 / \mu \mathrm{g}$ cRNA) was fragmented at $60^{\circ} \mathrm{C}$ for 30 minutes in a reaction volume of $25 \mu \mathrm{l}$ containing $1 \mathrm{x}$ Agilent fragmentation buffer and $2 \mathrm{x}$ Agilent blocking agent following the manufacturer's instructions. On completion of the fragmentation reaction, $25 \mu \mathrm{l}$ of $2 \mathrm{x}$ Agilent hybridization buffer was added to the fragmentation mixture and hybridized to the $S$. cerevisiae microarrays slides for 17 hours at $65^{\circ} \mathrm{C}$ in an Agilent G2545A Hybridization Oven and on Agilent Rotator Rack. After hybridization, microarrays were sequentially washed: 1 minute at room temperature with GE Wash Buffer 1 (Agilent) and 1 minute with $37^{\circ} \mathrm{C} \mathrm{GE}$ Wash buffer 2 (Agilent), then a 10 seconds Acetonitrile Wash (Agilent) followed by a 30 seconds Stabilization and Drying Solution wash (Agilent). Slides were immediately subjected to fluorescent detection using fluorescent detection with a GenePix 4000B (Molecular Devices, USA) with simultaneously scanning the Cy3 and Cy5 channels at a resolution of $5 \mu \mathrm{m}$. Laser was set at $100 \%$ and PMT gain was adjusted automatically for each slide using the program GenePix Pro (Molecular Device) according to the signal intensity of each array. Merged Cy3 and Cy5 TIFF images generated by the GenePix Pro were used to analysis in the Agilent Feature Extraction software (version 9.5.3.1, Agilent) using Linear Lowess algorithm to obtain background subtracted and normalized intensity values. The dye-normalyzed values generated in the Feature Extraction data files were used to upload the software Express Converter (version 2.1, TM4 available at http://www.tm4.org/utilities.html) which conveniently converts the Agilent file format to mev (multi experiment view) file format compatible to the TM4 softwares for microarray analysis (available at http://www.tm4.org/). The mev files were then uploaded in the MIDAS software where the resulting data were averaged from replicated genes on each array, from dyeswap hybridizations for each experiment and from two biological replicates using the tools "flip dye consistency cheking" and "in slides replicates analysis" implemented in MIDAS software. The mev files generated were then loaded in MEV software (MultiExperiment Viewer) where differentially expressed genes were identified using one-class $t$-test $(p>0.01)$. Significantly different genes were those whose mean $\log _{2}$ expression ratio over all included samples was statistically different from 0 which indicates the absence of gene modulation. The genes significantly up- or down-regulated in the microarray analysis was subjected to Gene Ontology analysis using the GO Term Finder tool available at the Saccharomyces Genome Database (SGD <http://www.yeastgenome.org >).

\section{Physical protein-protein (PPPI) network design and global topological analysis}

The transcriptomic data gathered from yeast BY4742 strain submitted to propolis treatment was used to obtain information about how the under- and overexpressed genes and their products interact in the context of physical protein-protein interactions (PPPI networks) in $S$. cerevisiae. In this sense, the data mining screening and network design of repressed or induced genesassociated PPPI networks was performed using Cytoscape software, version 2.6.3 [20]. For this purpose, we used the PPPI data of $S$. cerevisiae available in the Saccharomyces Genome Database (http://www.yeastgenome. org). The induced and repressed PPPI networks obtained from this first screening were then combined in a unique PPPI network by employing the union function of the Cytoscape core plugin Merge Networks. The union PPPI network was then analyzed with molecular complex detection (MCODE) software [21], a Cytoscape plug-in (at http://apps.cytoscape.org/apps/mcode) in order to detect clusters of proteins that could represent distinct biologic processes. The parameters used for MCODE to generate the sub networks were as follows: loops included; degree cutoff of 2; deletion of single connected nodes from cluster (haircut option enabled); expansion of cluster by one neighbor shell allowed (fluff option enable); node density cutoff of 0.1 ; node score cutoff of $0.2 ; k$-core of 2 ; and maximum depth of network of 100 . The degree of data overlapping between induced- and repressedassociated PPPI networks was obtained from an areaproportional Venn diagram analysis, available at <http:// bioinforx.com/free/bxarrays/overlap.php>.

\section{Network centralities and local topological analyses}

Two major network centralities (node degree and betweenness) were computed from the merged network and clusters using the Cytoscape plugin CentiScaPe 1.0 [22]. The local topology of the network, defined as bottlenecks, was obtained from the threshold generated by each centrality calculated by CentiScape 1.0. In this sense, bottlenecks were defined as nodes with a value above the threshold calculated for node degree and betweenness.

\section{Gene ontology analysis}

Gene ontology (GO) clustering analysis was performed using Biological Network Gene Ontology (BiNGO) [23] software, a Cytoscape plugin available at http://chianti. ucsd.edu/cyto_web/plugins/index.php. The degree of functional enrichment for a given cluster and category was quantitatively assessed ( $p$ value) by hypergeometric distribution [24] and a multiple test correction was applied using the false discovery rate (FDR) [25] algorithm, fully implemented in BiNGO software. Overrepresented 
biological process categories were generated after FDR correction, with a significance level of 0.05 .

\section{Results and discussion Microarray hybridization analysis}

To our knowledge, previous to our work there is only a single study in the literature reporting transcriptional profiling for eukaryotic cells exposed to propolis [26]. In this study, propolis was applied for 24 hours to normal human dermal fibroblast and keratinocytes. These authors were able to identify 205 genes important for skin and only 5 (ATP citrate synthase, aquaporin 3, cytochrome $c$ oxidase 1 , nitric oxide synthase 3 , and hydroxylase 3) and 1 (progestone receptor) that appear to be up- and down regulated in both cell lines, respectively. We have been using S. cerevisiae as an eukaryotic model system to identify genes that are important for propolismediated cell death. As previously shown, when S. cerevisiae exponential cells are exposed to propolis $0.125 \%$ for 5 and 10 minutes, there is a decreased survival of 24.1 and $6.3 \%$, respectively in comparison to the propolis-untreated control containing only $0,68 \%$ ethanol [17]. To gain an insight on which pathways are modulated during S. cerevisiae exposure to propolis, we determined its transcriptional profiling. Total RNA extracted from these cultures was used to generate fluorescent-labeled cRNAs for competitive microarray hybridizations. All the controls for further experiments using propolis $0.125 \%$ as a treatment have $0.68 \%$ ethanol (reference samples). We have compared the mRNA expression of the S. cerevisiae BY4742 strain grown for 9 hours and exposed to $0.125 \%$ propolis for 5 and $10 \mathrm{~min}$ utes with yeast cells exposed to 5 and 10 minutes $0.68 \%$ ethanol. In these experiments, the main aim was to focus on genes that have increased or decreased mRNA expression. The full dataset was deposited in the Gene Expression Omnibus (GEO) from the National Center of Biotechnology Information (NCBI) with the number GSE33971 (http://www.ncbi.nlm.nih.gov/projects/geo/ query/acc.cgi?acc $=$ GSE33971). We were able to observe 1,399 genes modulated in at least one time point ( $p$ value 0.01 , calculated FDR is $2.1 \%$ ) when compared to the respective reference time (reference untreated samples obtained under the control experimental conditions, i. e., $2 \times 10^{7}$ cells $\mathrm{ml}^{-1}$ exposed only to $0.68 \%$ ethanol for 5 or 10 minutes). We have used Gene Ontology (GO) Term Finder analysis aiming to classify the main biological processes associated to the list of the up- and down-regulated genes identified in the microarray hybridizations. In addition, we assessed the probability values of the over-abundance of the GO groups compared to the genomic average in order to gain information about the statistical significance of overrepresented processes $(p<0.05)$. Table 1 shows the adjusted $p$-values indicating the categories of genes overrepresented in the microarray analysis which are involved in a variety of cellular processes. To have a broader view of the most significant modulated genes found in the microarray analysis, we listed the genes having increased or decreased mRNA expression with $\log$ ratios $\geq 1$ (203 genes) or $\leq 1$ (136 genes). These genes were grouped according to the GO identity obtained in Table 1 [Additional file 1: Table A1 shows the genes with $\log$ ratios $\geq 1$ (203 genes) or $\leq 1$ (136 genes), respectively]. The Table 2 shows a list of chosen genes presenting higher level of up-regulation in the microarray which were grouped into categories of significantly overrepresented biological process according to the gene ontology ID shown in Table 1. Interestingly, inside the enriched category "transmembrane transport and localization" (GO:0055085 and GO:0051179; $p<0.01$ ), we have observed several genes encoding transporters reported as involved in multidrug resistance (MDR; for reviews see [27-30], suggesting propolis can activate at the transcriptional level the complex set of genes responsible for MDR in S. cerevisiae (Table 2 and Additional file 1: Table A1). In addition, we have also observed enrichment for genes encoding proteins important for the assembly of the vacuolar ATPase and the endocytic pathway (Table 2 and Additional file 1: Table A1). None of the deletion mutants for these transporter encoding genes shown in Additional file 1: Table A1 were observed as more sensitive to propolis, except for TPO1 [17], indicating a redundant transcriptional response of these genes to propolis. However, we have previously observed that when several genes involved in the assembly of the yeast V-ATPase such as VPH1, $V M A 3,4,5,11,22, R A V 1$ and SOP4 were deleted, the corresponding yeast deletion strains became more sensitive to propolis [17].

Earlier, by screening a non essential yeast deletion library, we observed that most of the proteins whose deletion increases the sensitivity of yeast strains to propolis are involved in cell division mechanisms, mitochondrial electron transport chain, vacuolar acidification, regulation of macroautophagy associated with protein target to vacuole, cellular response to starvation, and negative regulation of transcription from RNA polymerase II promoter [17]. We have shown that propolis induces vacuolar acidification and translocation of Atg8p to the vacuoles, one of the hallmarks of autophagy [17]. In $S$. cerevisiae, the vacuole is very important for keeping cellular homeostasis comprising the regulation of intracellular $\mathrm{pH}$ and degradation mainly during nutrient limitation of proteins and organelles by autophagy (for reviews, see [31-33]). Cell death induced by acetic acid is increased in S. cerevisiae VPS gene deletion mutants (VPS genes are involved in homotypic vacuole fusion, 
Table 1 Overrepresented categories of the significantly modulated (up- and down-regulated) genes found in the microarray hybridization based on the genome coverage $(p<0.05)$

\begin{tabular}{|c|c|c|c|}
\hline GOID & TERM & CORRECTED $P$-VALUE & FDR RATE \\
\hline GO:0009987 & cellular process & 3.57E-09 & $0.00 \%$ \\
\hline GO:0065007 & biological regulation & 7.91E-09 & $0.00 \%$ \\
\hline GO:0050794 & regulation of cellular process & $1.58 \mathrm{E}-07$ & $0.00 \%$ \\
\hline GO:0050789 & regulation of biological process & $7.16 \mathrm{E}-07$ & $0.00 \%$ \\
\hline GO:0051276 & chromosome organization & $1.30 \mathrm{E}-06$ & $0.00 \%$ \\
\hline GO:0006996 & organelle organization & 2.25E-06 & $0.00 \%$ \\
\hline GO:0071841 & $\begin{array}{l}\text { cellular component organization or } \\
\text { biogenesis at cellular level }\end{array}$ & $2.66 \mathrm{E}-06$ & $0.00 \%$ \\
\hline GO:0071842 & cellular component organization at cellular level & $3.14 \mathrm{E}-06$ & $0.00 \%$ \\
\hline GO:0022402 & cell cycle process & $3.16 \mathrm{E}-06$ & $0.00 \%$ \\
\hline GO:0007049 & cell cycle & 4.76E-06 & $0.00 \%$ \\
\hline GO:0071840 & cellular component organization or biogenesis & $5.08 \mathrm{E}-06$ & $0.00 \%$ \\
\hline GO:0022403 & cell cycle phase & $5.56 \mathrm{E}-06$ & $0.00 \%$ \\
\hline GO:0006351 & transcription, DNA-dependent & $1.13 \mathrm{E}-05$ & $0.00 \%$ \\
\hline GO:0032774 & RNA biosynthetic process & $1.28 \mathrm{E}-05$ & $0.00 \%$ \\
\hline GO:0016043 & cellular component organization & $1.95 \mathrm{E}-05$ & $0.00 \%$ \\
\hline GO:0000279 & M phase & $1.98 \mathrm{E}-05$ & $0.00 \%$ \\
\hline GO:0007059 & chromosome segregation & $2.94 \mathrm{E}-05$ & $0.00 \%$ \\
\hline GO:0010556 & regulation of macromolecule biosynthetic process & 3.70E-05 & $0.00 \%$ \\
\hline GO:0060255 & regulation of macromolecule metabolic process & 4.61E-05 & $0.00 \%$ \\
\hline GO:0019219 & $\begin{array}{l}\text { regulation of nucleobase-containing } \\
\text { compound metabolic process }\end{array}$ & 4.64E-05 & $0.00 \%$ \\
\hline GO:2000112 & regulation of cellular macromolecule biosynthetic process & 4.86E-05 & $0.00 \%$ \\
\hline GO:0051171 & regulation of nitrogen compound metabolic process & 4.96E-05 & $0.00 \%$ \\
\hline GO:0006807 & nitrogen compound metabolic process & $6.46 \mathrm{E}-05$ & $0.00 \%$ \\
\hline GO:0051252 & regulation of RNA metabolic process & 0.000109266 & $0.00 \%$ \\
\hline GO:0034641 & cellular nitrogen compound metabolic process & 0.000114855 & $0.00 \%$ \\
\hline GO:0006325 & chromatin organization & 0.00011847 & $0.00 \%$ \\
\hline GO:0009889 & regulation of biosynthetic process & 0.00012496 & $0.00 \%$ \\
\hline GO:0031326 & regulation of cellular biosynthetic process & 0.00012496 & $0.00 \%$ \\
\hline GO:0000278 & mitotic cell cycle & 0.000140145 & $0.00 \%$ \\
\hline GO:0006355 & regulation of transcription, DNA-dependent & 0.000140184 & $0.00 \%$ \\
\hline GO:2001141 & regulation of RNA biosynthetic process & 0.000140184 & $0.00 \%$ \\
\hline GO:0048285 & organelle fission & 0.00015597 & $0.00 \%$ \\
\hline GO:0007067 & mitosis & 0.000167729 & $0.00 \%$ \\
\hline GO:0000280 & nuclear division & 0.000263661 & $0.00 \%$ \\
\hline GO:0080090 & regulation of primary metabolic process & 0.000279393 & $0.00 \%$ \\
\hline GO:0006139 & nucleobase-containing compound metabolic process & 0.000384242 & $0.00 \%$ \\
\hline GO:0065003 & macromolecular complex assembly & 0.001007045 & $0.00 \%$ \\
\hline GO:0031323 & regulation of cellular metabolic process & 0.00115049 & $0.00 \%$ \\
\hline GO:0000087 & M phase of mitotic cell cycle & 0.001853624 & $0.00 \%$ \\
\hline GO:0019222 & regulation of metabolic process & 0.002020633 & $0.00 \%$ \\
\hline GO:0043933 & macromolecular complex subunit organization & 0.002159081 & $0.00 \%$ \\
\hline GO:0050896 & response to stimulus & 0.002997939 & $0.00 \%$ \\
\hline GO:0051179 & localization & 0.003108437 & $0.00 \%$ \\
\hline
\end{tabular}


Table 1 Overrepresented categories of the significantly modulated (up- and down-regulated) genes found in the microarray hybridization based on the genome coverage $(\mathbf{p}<\mathbf{0 . 0 5})$ (Continued)

\begin{tabular}{llll}
\hline GO:0033043 & regulation of organelle organization & 0.00356682 & $0.00 \%$ \\
\hline GO:0048523 & negative regulation of cellular process & 0.003751468 & $0.00 \%$ \\
\hline GO:0010468 & regulation of gene expression & 0.004560142 & $0.00 \%$ \\
\hline GO:0016568 & chromatin modification & 0.006683962 & $0.00 \%$ \\
\hline GO:0048519 & negative regulation of biological process & 0.006744751 & $0.00 \%$ \\
\hline GO:0034622 & cellular macromolecular complex assembly & 0.007563808 & $0.00 \%$ \\
\hline GO:0006950 & response to stress & 0.009479328 & $0.00 \%$ \\
\hline GO:0055085 & transmembrane transport & 0.011885843 & $0.00 \%$ \\
\hline GO:0006366 & transcription from RNA polymerase II promoter & 0.01881881 & $0.00 \%$ \\
\hline GO:0010604 & positive regulation of macromolecule metabolic process & 0.021216691 & $0.00 \%$ \\
\hline GO:0034621 & cellular macromolecular complex subunit organization & 0.024007449 & $0.00 \%$ \\
\hline GO:0016070 & RNA metabolic process & 0.026116229 & $0.00 \%$ \\
\hline GO:0009058 & biosynthetic process & 0.028171132 & $0.00 \%$ \\
\hline GO:0051173 & positive regulation of nitrogen compound metabolic process & 0.032491519 & $0.00 \%$ \\
\hline GO:0000819 & sister chromatid segregation & 0.033192255 & $0.00 \%$ \\
\hline GO:0009893 & positive regulation of metabolic process & 0.034622731 & $0.00 \%$ \\
\hline GO:0031325 & positive regulation of cellular metabolic process & 0.035672319 & $0.00 \%$ \\
\hline
\end{tabular}

Enrichment analysis was performed using the GO Term Finder available at < http://go.princeton.edu/cgi-bin/GOTermFinder $>$ for searching for significant shared $\mathrm{GO}$ terms to describe the gene list of the significantly modulated genes $(\mathrm{p}<0.05)$. The input list for the analysis comprised 1,399 representing the total of up-and down-regulated found in the microarray analysis. FDR is the percentage of the GO terms with p-values as good as or better than a particular GO term with this FDR would be expected to be false positives.

vacuolar protein sorting and are essential for normal vacuolar function) [34]. It has been observed that the intracellular $\mathrm{pH}$ was acidified in VPS mutant cells upon treatment with acetic acid [34]. It is possible the disturbance of the homeostatic $\mathrm{pH}$ control may trigger necrosis by release of pro-necrotic proteases, which would find an optimal $\mathrm{pH}$ for their enzymatic activity in the acidified cytosol [35]. We have observed genes encoding proteins important for ROS detoxification in $S$. cerevisiae significantly enriched in the microarray hybridization (GO: GO:0006950; Response to Stress and (GO:0050896) Response to Stimulus; Table 2 and Additional file 1: A1; $<<0.003)$ such as GRX4, GTT2, GTT3, TSA2, DFM1, and TRX1 with increased mRNA accumulation when S. cerevisiae is exposed to $0.125 \%$ propolis. Interestingly, there is also an increased mRNA accumulation of genes encoding proteins involved in the generation of ATP into the mitochondria, such as ATP17, ATP18, ATP19, ATP20, ATP21, and COX8 grouped in the category of cellular component organization or biogenesis at cellular level (GO:0071841; Table 2 and Additional file 1: Table A1; $p<2.66 \times 10^{-6}$ ). There are several conditions where mitochondriaproduced ROS have been associated to yeast apoptosis (for reviews, see [35-38]). Propolis at $0.125 \%$ can induce ROS formation and it is more lethal when $S$. cerevisiae grows in the presence of glycerol and ethanol as carbon sources [17], suggesting that respiration increases propolis lethality. Interestingly, it was observed as up- regulated into the same enriched category the gene OYE3 (old yellow enzyme) which was described as involved in increased resistance to $\mathrm{H}_{2} \mathrm{O}_{2}$-induced programmed cell death in yeast [39].

Moreover, there are several genes related to cell cycle and cell cycle process and chromosome distribution and chromatin silencing that have decreased mRNA accumulation when $S$. cerevisiae is exposed to propolis (Table 3 and Additional file 1: Table A1). The reduced mRNA abundance of these genes suggested propolis is activating transcriptional checkpoint controls involved in the S- and M-phases important for DNA replication and proper chromosome segregation.

\section{Validation of the microarray hybridization analysis}

To validate some of our findings, we have chosen six different genes from our microarray analysis whose mRNA has either increased or decreased abundance when $S$. cerevisiae is exposed to $0.125 \%$ propolis. We designed Lux fluorescent probes and used real-time RT-PCR analysis to quantify their expression in a new set of biological replicate of the mRNA isolated from 5 and 10 minutes exposure to $0.125 \%$ propolis and compared them with the corresponding 5 and 10 minutes exposure to $0.68 \%$ ethanol. We have used as a normalizer control, TAF10, a gene encoding a subunit $(145 \mathrm{kDa})$ of TFIID and SAGA complexes, involved in RNA polymerase II transcription initiation and in chromatin modification. Recently, this gene was shown as an appropriate 
Table 2 Selected genes more expressed $(\log 2 \geq 1.0)$ during $S$. cerevisiae exposure to propolis according to the GO term finder enrichment analysis (for a complete list of the genes more expressed, see Additional file 1: Table

\section{A1)}

Transmembrane Transport (GO:0055085) and Localization (GO:0051179) $(p<0.011)$

\begin{tabular}{|c|c|}
\hline$\overline{\text { FLR1 }}$ & $\begin{array}{l}\text { Multidrug transporter of the MFS, involved in efflux of } \\
\text { fluconazole, diazaborine, benomyl, methotrexate, } \\
\text { and other drugs }\end{array}$ \\
\hline PDR15 & $\begin{array}{l}\text { ATP binding cassette }(A B C) \text { transporter, multidrug } \\
\text { transporter and general stress response factor implicated } \\
\text { in cellular detoxification }\end{array}$ \\
\hline$\overline{\text { AZR1 }}$ & $\begin{array}{l}\text { Transporter of the MFS, involved in resistance to azole } \\
\text { drugs such as ketoconazole and fluconazole }\end{array}$ \\
\hline$\overline{\text { YOR1 }}$ & $\begin{array}{l}\text { ATP-binding cassette }(\mathrm{ABC}) \text { transporter, multidrug } \\
\text { transporter mediates export of many different organic } \\
\text { anions including oligomycin }\end{array}$ \\
\hline PDR10 & $\begin{array}{l}\text { ATP-binding cassette (ABC) transporter, multidrug } \\
\text { transporter involved in the pleiotropic drug } \\
\text { resistance network }\end{array}$ \\
\hline PDR12 & $\begin{array}{l}\text { ATP-binding cassette (ABC) transporter, weak-acid-inducible } \\
\text { multidrug transporter required for weak organic } \\
\text { acid resistance }\end{array}$ \\
\hline ENA1 & $\begin{array}{l}\text { P-type ATPase sodium pump, involved in } \mathrm{Na}+\text { and } \mathrm{Li}+ \\
\text { efflux to allow salt tolerance }\end{array}$ \\
\hline ENA2 & $\begin{array}{l}\text { P-type ATPase sodium pump, involved in } \mathrm{Na}+\text { efflux to } \\
\text { allow salt tolerance; likely not involved in } \mathrm{Li}+\text { efflux }\end{array}$ \\
\hline VMA21 & $\begin{array}{l}\text { Membrane protein that is required for vacuolar } \mathrm{H}+- \text { ATPase } \\
\text { (V-ATPase) function, although not an actual component of } \\
\text { the V-ATPase }\end{array}$ \\
\hline$\overline{\mathrm{TPO} 1}$ & $\begin{array}{l}\text { Polyamine transporter (MFS) that recognizes spermine, } \\
\text { putrescine, and spermidine }\end{array}$ \\
\hline TPO4 & $\begin{array}{l}\text { Polyamine transport protein (MFS) recognizes spermine, } \\
\text { putrescine, and spermidine }\end{array}$ \\
\hline ATG22 & $\begin{array}{l}\text { Vacuolar integral membrane protein required for efflux of } \\
\text { amino acids during autophagic body breakdown } \\
\text { in the vacuole }\end{array}$ \\
\hline VMA7 & $\begin{array}{l}\text { Subunit F of the eight-subunit V1 peripheral membrane } \\
\text { domain of vacuolar H+-ATPase (V-ATPase) }\end{array}$ \\
\hline PKR1 & $\begin{array}{l}\text { V-ATPase assembly factor, functions with other V-ATPase } \\
\text { assembly factors in the ER to efficiently assemble the } \\
\text { V-ATPase }\end{array}$ \\
\hline
\end{tabular}

\begin{tabular}{ll}
\hline $\begin{array}{l}\text { Response to Stress (GO:0006950) and Response to Stimulus } \\
\text { (GO:0050896) ( } \mathbf{p}<\mathbf{0 . 0 0 9 )}\end{array}$ \\
\hline GRX4 & $\begin{array}{l}\text { Hydroperoxide and superoxide-radical responsive } \\
\text { glutathione-dependent oxidoreductase }\end{array}$ \\
\hline GTT3 & $\begin{array}{l}\text { Protein of unknown function with a possible role in } \\
\text { glutathione metabolism }\end{array}$ \\
\hline TSA2 & $\begin{array}{l}\text { Stress inducible cytoplasmic thioredoxin peroxidase; } \\
\text { cooperates with Tsa1p in the removal of reactive oxygen }\end{array}$ \\
\hline GTT2 & $\begin{array}{l}\text { Glutathione S-transferase capable of homodimerization; } \\
\text { functional overlap with Gtt2p, Grx1p, and Grx2p }\end{array}$ \\
\hline GND2 & $\begin{array}{l}\text { 6-phosphogluconate dehydrogenase, catalyzes an NADPH } \\
\text { regenerating reaction in the pentose phosphate pathway }\end{array}$ \\
\hline TRX1 & $\begin{array}{l}\text { Cytoplasmic thioredoxin isoenzyme of the thioredoxin } \\
\text { system which protects cells against oxidative } \\
\text { and reductive stress }\end{array}$ \\
\hline
\end{tabular}

Table 3 Selected genes less expressed $(\log 2 \leq-1.0)$ during $S$. cerevisiae exposure to propolis according to the GO term finder enrichment analysis (for a complete list of the genes less expressed, see Additional file 1:

\section{Table A1)}

Cell cycle (GO:0007049) and Cell cycle process (GO: 0022402)

\section{$\left(p<4.76 \times 10^{-6}\right)$}

\section{SMC4 Subunit of the condensin complex; reorganizes} chromosomes during cell division

MCM10 Essential chromatin-associated protein involved in the initiation of DNA replication

\section{CIN8 Kinesin motor protein involved in mitotic spindle assembly} and chromosome segregation

IBD2 Component of the BUB2-dependent spindle checkpoint pathway, interacts with Bfalp and functions upstream of Bub2p and Bfa1p

BRN1 Subunit of the condensin complex; required for chromosome condensation and for clustering of tRNA genes at the nucleolus

CEP3 Essential kinetochore protein, component of the CBF3 complex that binds the CDEIII region of the centromere

SLK19 Kinetochore-associated protein required for normal segregation of chromosomes in meiosis and mitosis

NSL1 Component of the MIND kinetochore complex which joins kinetochore subunits contacting DNA to those contacting microtubules

SPC24 Component of the evolutionarily conserved kinetochore-associated $\mathrm{Ndc80}$ complex

HOS2 Histone deacetylase required for gene activation via specific deacetylation of lysines in $\mathrm{H} 3$ and $\mathrm{H} 4$ histone tails

ESA1 Catalytic subunit of the histone acetyltransferase complex (NuA4) that acetylates four conserved internal lysines of histone $\mathrm{H} 4$

MAM1 Monopolin, kinetochore associated protein involved in chromosome attachment to meiotic spindle

\section{Chromosome organization (GO:0051276) $\left(\mathrm{p}<1.30 \times 10^{-6}\right)$}

RLF2 Largest subunit (p90) of the Chromatin Assembly Complex (CAF-1) and Msi1p that assembles newly synthesized histones

SGF29 Probable subunit of SAGA histone acetyltransferase complex

RNA metabolic process (GO:0016070) and RNA biosynthetic process (GO:0009058) $(p<0.02)$

LEO1 Component of the Paf1 complex, which associates with RNA polymerase II and is involved in histone methylation

\begin{tabular}{ll}
\hline SPT21 & $\begin{array}{l}\text { Protein required for normal transcription at several loci } \\
\text { including HTA2-HTB2 and HHF2-HHT2 }\end{array}$ \\
\hline RFM1 & $\begin{array}{l}\text { Specificity factor that directs the Hst1p histone deacetylase } \\
\text { to some of the promoters regulated by Sum1p }\end{array}$ \\
\hline IES2 & $\begin{array}{l}\text { Protein that associates with the INO80 chromatin remodeling } \\
\text { complex under low-salt conditions }\end{array}$ \\
\hline IFH1 & $\begin{array}{l}\text { IFH1 exhibits genetic interactions with FHL1, overexpression } \\
\text { interferes with silencing at telomeres and HM loc }\end{array}$ \\
\hline NGG1 & $\begin{array}{l}\text { component of transcriptional adaptor and histone } \\
\text { acetyltransferase complexes, the ADA, the SAGA, and the } \\
\text { SLIK complexes }\end{array}$ \\
\hline
\end{tabular}


reference gene for quantitative gene expression analysis by real-time RT-PCR [40]. In addition, TAF10 was not shown as modulated in our microarray hybridization experiments (data not shown). Thus, the measured quantity of a specific gene mRNA in each of the treated samples was normalized using the $C_{T}$ values obtained for the TAF10 mRNA amplifications run in the same plate. The results were expressed as the number of times the genes have increased or decreased abundance when the yeast strains were exposed to propolis compared to the ethanol treatment (Figure 1).

Due to the apparent importance of the enriched genes in the categories of (i) cellular component organization or biogenesis; (ii) transmembrane transport; (iii) response to stress/stimulus and (iv) cellular component organization or biogenesis, we evaluated the mRNA abundance of (i) PDR15 (YDR406W) encoding a transporter involved in multidrug resistance; (ii) SNQ2
(YDR011W) encoding a plasma membrane ATP-binding cassette $(\mathrm{ABC})$ transporter, multidrug transporter involved in multidrug resistance and resistance to singlet oxygen species; (iii) TIM10 (YHR005C-A) encoding and essential protein of the mitochondrial intermembrane space, that forms a complex with Tim9p (TIM10 complex) and delivers hydrophobic proteins to the TIM22 complex for insertion into the inner membrane; (iv) VMA7 (YGR020C) and (v) VMA21 (YGR105W). These genes respectively encodes the subunit $\mathrm{F}$ of the eightsubunit V1 peripheral membrane domain of vacuolar $\mathrm{H}^{+}$-ATPase (V-ATPase) and Integral membrane protein that is required for vacuolar $\mathrm{H}+-\mathrm{ATPase}$ (V-ATPase) function. The gene $R L F 2$ (YPR018W) was also analyzed but different from the previous chosen genes, RLF2 was observed as down-regulated in the microarray analysis (Additional file 1: Table A1; Chromosome organization (GO:0051276; $p<1.3 \times 10^{-6}$ ). RLF2 encodes the largest


Figure 1 Real-time RT-PCR for selected genes from the microarray hybridization analysis. S. cerevisiae was grown for 9 hours in liquid YPD at $30^{\circ} \mathrm{C}$ and the cells $\left(\sim 2 \times 10^{7} \mathrm{cells} \mathrm{ml}^{-1}\right)$ were transferred to fresh liquid YPD and exposed to propolis $0.125 \%$ for 5 or 10 minutes. The relative quantitation of RLF2 (A), PDR15 (B), TIM10 (C), SNQ2 (D), VMA7 (E), VMA21 (F) was performed using TAF10 as normalizer. Gene expression was determined by a standard curve (i.e., $C_{T}$-values plotted against logarithm of the DNA copy number). The results are the means \pm standard deviation of four sets of experiments using completely independent biological replicates. The values above the bars are mean of the log2-ratio obtained in the microarray hybridization experiments. 
subunit (p90) of the Chromatin Assembly Complex (CAF-1) with Cac2p and Msi1p that assembles newly synthesized histones onto recently replicated DNA.

As expected, all five genes that showed increased mRNA abundance (PDR15, TIM10, SNQ2, VMA7, and $V M A 21)$ and decreased mRNA abundance (RLF2) in the microarray hybridization analysis grouped in its respective enrichment categories showed corresponding increase and decreased expression in the real-time PCR experiments (Figure 1A-F). This behavior is in accordance with the normalized mean values obtained in the microarray analysis (see values above the Figure 1 graphs for comparison). Thus, it seems that our microarray hybridization approach is capable of providing information about $S$. cerevisiae gene expression modulation with a considerably high level of confidence and is an open source of data for further investigation for the mechanisms of propolis-mediated cell death in all susceptive organisms.

\section{Systems analysis for propolis exposure}

The transcriptomics data obtained submitted to the treatment conditions described in this work prompt us to ask how the underexpressed or overexpressed genes affect different biological processes that are altered during the exposure to $0.125 \%$ propolis. In this sense, a search for potential proteins and/or mechanisms and their associated biological processes that are affected by the conditions treatment was initiated. To achieve this goal, two different PPPI networks using yeast transcriptomics data were retrieved from Saccharomyces Genome Database (SGD): one associated to repressed genes (136 genes; repressed genes-associated PPPI network) and one associated to induced genes (203 genes; induced genes-associated network). The induced genesassociated PPPI network obtained from SGD contains 1,226 nodes and 2,854 connectors while the repressedassociated gene PPPI network contains 1,412 nodes and 2,782 connectors (Additional file 2: Table A2). Both induced- and repressed-genes associated PPPI networks were analyzed in order to observe the degree of network overlapping by means of an Area proportional Venn diagram. This analysis indicated that the repressed-genes associated PPPI network contains 919 unique proteins, while the induced-genes associated network contains 733 unique proteins, and there are 493 overlapping proteins. Although the degree of network overlapping was not elevated, we decided to merge both networks in a unique graph, containing 2,158 nodes and 5,655 connectors (Figure 2 and Additional file 2: Table A2). Sub networks (clusters) present in the union PPPI network were identified and retrieved using the Cytoscape-associated plugin MCODE and subjected to a Gene Ontology (GO) analysis in order to obtain information about the nature and number of sub graphs belonging to the network and their associated biological processes. The union PPPI network contains eleven interconnected clusters, each comprising different biological processes. GO analysis of the obtained clusters indicated the participation of important biological processes that can be seen in Table 4 and Additional file 3: Table A3. Many of these processes are reflecting the results previously found in the yeast library screening such as cell division mechanisms, mitochondria, vacuolar acidification, negative regulation of transcription from RNA polymerase II promoter (17). In addition, other important processes such as protein transport and membrane organization and biogenesis (Table 4, cluster 3); transcription from RNA polymerase II promoter and transcription, DNA dependent (Table 4, cluster 4), regulation of cell cycle (Table 4, cluster 7); ATP metabolic process, proton transport and vacuolar acidification (Table 4, cluster 9) and response to stress (Table 4, cluster 10) were categories also observed in the microarray hybridization analysis (see Additional file 3: Table A3 for a complete description of genes). It is also important to mention that statistically significant modulated genes could be observed in each of these clusters indicating that the PPPI network could link the transcriptomic analysis to potential biological processes affected by propolis. These genes can be seen in Additional file 3: Table A3 [written in red (repressed) or green (induced)].

Based on data gathered from this initial systems biology tools analysis, we decided to get more information about the major nodes involved in the information of the network using network centralities. Network centralities allow us to identify nodes (and the consequent biological processes) that have a relevant position in the overall network architecture [41]. Centralities have been recently applied to quantify the centrality and prestige of actors in social networks [41] and to understand the structure and properties of complex biological, technological and infrastructural networks $[42,43]$. Many of the nodes in a given network that show elevated values of centrality are important points of vulnerability, indicating that any attack to these nodes could introduce strong perturbations in the network. Node degree represents the simplest centrality measure in a given network, corresponding to the number of nodes adjacent to a given node, where adjacent means directly connected [22]. The node degree represents the "popularity" of a given node, and highly connected nodes in a network are termed hubs. Next, betweenness is a measure that indicates to what extent a specific node is between all other nodes within the network [44]. In a general sense, betweenness show the influence of a node over the spread of information throughout the network. On the other hand, bottleneck is a local topologic data that is 


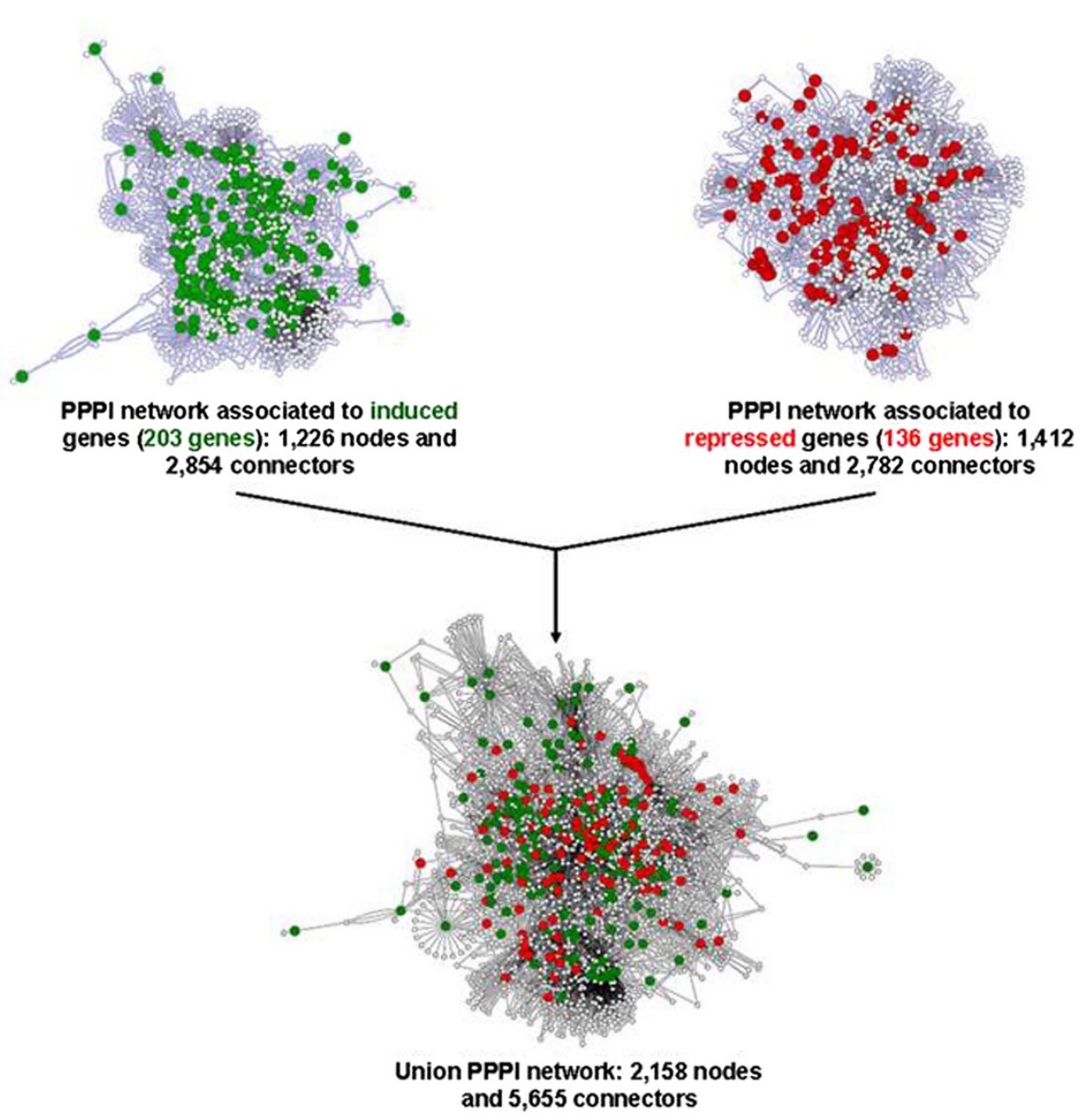

Figure 2 Design of the union network generated from repressed- and induced-associated gene PPPI networks. Green nodes indicate proteins of genes that were induced in the array, while red nodes are associated to proteins of genes that were repressed in the array.

defined as all nodes with high betweenness values and different nodes degrees, indicating that those nodes are central points that control the communication between other nodes within the network [45,46]. The measures of betweenness and node degree allow us to define the bottleneck nodes. Bottleneck nodes correspond to highly central proteins that connect several complexes or are peripheral members of central complexes, being important communication points between two complexes [46]. Mostly of bottleneck nodes tend to be essential proteins in a network [46].

The centrality analysis of union network indicated the presence of 419 bottleneck nodes; 99 of these bottleneck nodes correspond to proteins of genes that were induced in array and 92 that were repressed in array (see Additional file 4: Table A4, spreadsheet 1). The centrality analysis was also made for the 11 clusters (Additional file 4: Table A4, spreadsheet 2). This analysis showed the presence of important bottleneck nodes in the clusters. Several genes that encode many of these proteins characterized as Bottleneck nodes (i. e. essential proteins in a network) were previously described in Tables 2, 3 and Additional file 1: Table A1 once again highlighting the significance of the biological process identified as involved in response and cell tolerance to propolis. Thus, the main bottleneck nodes can be observed in Table 5 and are related to the following biological processes: cellular component organization or biogenesis, transmembrane transport, response to stress (referring to genes induced in the microarray analysis) and chromosome organization, cell cycle, RNA metabolic process (referring to genes repressed in the microarray analysis). To verify the biological processes associated with these genes, see Additional file 1: Table A1.

These data express the importance of these pathways in response of $S$. cerevisiae to propolis and confirm a high degree of overlapping in gene function among the microarray hybridization and the system biology analysis. Furthermore, the data obtained here confirms the results achieved through the identification of genes involved in propolis sensitivity by the screening of the S. cerevisiae non-essential deletion library previously reported [17]. 
Table 4 Main specific gene ontology categories observed in clusters derived from union PPPI network

\begin{tabular}{|c|c|c|c|c|c|c|}
\hline & Biological process & GOID & $P$-value ${ }^{a}$ & Corrected $\mathrm{P}$ value $^{\mathrm{b}}$ & $k^{c}$ & $f^{d}$ \\
\hline \multirow[t]{3}{*}{ Cluster 1} & Translation & 6416 & $2.07 \times 10^{-45}$ & $2.93 \times 10^{-43}$ & 45 & 499 \\
\hline & Ribosome assembly & 42255 & $1.82 \times 10^{-9}$ & $2.58 \times 10^{-8}$ & 9 & 65 \\
\hline & Negative regulation of mRNA processing & 50686 & $8.25 \times 10^{-3}$ & $3.90 \times 10^{-2}$ & 1 & 1 \\
\hline \multirow[t]{5}{*}{ Cluster 2} & Organic acid transport & 15849 & $2.0594 \times 10^{-4}$ & $1.4107 \times 10^{-2}$ & 3 & 65 \\
\hline & Choline transport & 15871 & $1.8904 \times 10^{-3}$ & $3.2372 \times 10^{-2}$ & 1 & 1 \\
\hline & Betaine transport & 15838 & $1.8904 \times 10^{-3}$ & $3.2372 \times 10^{-2}$ & 1 & 1 \\
\hline & Ethanolamine transport & 34229 & $1.8904 \times 10^{-3}$ & $3.2372 \times 10^{-2}$ & 1 & 1 \\
\hline & Amino acid transport & 6865 & $3.4951 \times 10^{-3}$ & $4.7047 \times 10^{-2}$ & 2 & 48 \\
\hline \multirow[t]{4}{*}{ Cluster 3} & Mitochondrial transport & 6839 & $1.74 \times 10^{-10}$ & $3.88 \times 10^{-9}$ & 5 & 67 \\
\hline & Mitochondrion organization and biogenesis & 7005 & $2.6080 \times 10^{-8}$ & $2.9122 \times 10^{-7}$ & 5 & 179 \\
\hline & Protein transport & 15031 & $3.7859 \times 10^{-6}$ & $2.1138 \times 10^{-5}$ & 5 & 481 \\
\hline & Membrane organization and biogenesis & 16044 & $3.5801 \times 10^{-4}$ & $1.0903 \times 10^{-3}$ & 3 & 196 \\
\hline \multirow[t]{9}{*}{ Cluster 4} & Transcription from RNA polymerase II promoter & 6366 & $3.4996 \times 10^{-11}$ & $3.4296 \times 10^{-9}$ & 9 & 162 \\
\hline & Histone modification & 16570 & $1.1400 \times 10^{-9}$ & $2.2345 \times 10^{-8}$ & 7 & 92 \\
\hline & Establishment and/or maintenance of chromatin architecture & 6325 & $2.4536 \times 10^{-9}$ & $4.3719 \times 10^{-8}$ & 9 & 260 \\
\hline & Transcription, DNA-dependent & 6351 & $5.8940 \times 10^{-9}$ & $8.7746 \times 10^{-8}$ & 9 & 287 \\
\hline & G1 phase of mitotic cell cycle & 80 & $1.0490 \times 10^{-8}$ & $1.2850 \times 10^{-7}$ & 5 & 32 \\
\hline & Regulation of RNA metabolic process & 51252 & $1.5270 \times 10^{-8}$ & $1.5753 \times 10^{-7}$ & 11 & 614 \\
\hline & Chromosome organization and biogenesis & 7001 & $1.0393 \times 10^{-7}$ & $8.8567 \times 10^{-7}$ & 9 & 398 \\
\hline & Response to drug & 17035 & $3.3259 \times 10^{-3}$ & $1.1436 \times 10^{-2}$ & 3 & 121 \\
\hline & Cell cycle & 7049 & $1.1244 \times 10^{-2}$ & $3.5546 \times 10^{-2}$ & 5 & 566 \\
\hline \multirow[t]{5}{*}{ Cluster 5} & DNA catabolic process & 6308 & $7.6846 \times 10^{-5}$ & $6.1477 \times 10^{-4}$ & 2 & 30 \\
\hline & Meiotic recombination & 7145 & $2.8107 \times 10^{-4}$ & $1.6864 \times 10^{-3}$ & 2 & 57 \\
\hline & Double-strand break repair & 6302 & $3.0125 \times 10^{-4}$ & $1.7012 \times 10^{-3}$ & 2 & 59 \\
\hline & M phase of meiotic cell cycle & 51327 & $2.6749 \times 10^{-3}$ & $7.7814 \times 10^{-3}$ & 2 & 176 \\
\hline & Telomere maintenance via recombination & 722 & $9.7652 \times 10^{-3}$ & $2.5337 \times 10^{-2}$ & 1 & 19 \\
\hline Cluster 6 & ER to Golgi vesicle-mediated transport & 6888 & $6.1201 \times 10^{-4}$ & $2.5773 \times 10^{-2}$ & 2 & 84 \\
\hline \multirow[t]{7}{*}{ Cluster 7} & Negative regulation of RNA metabolic process & 51253 & $2.4984 \times 10^{-6}$ & $8.0002 \times 10^{-5}$ & 4 & 157 \\
\hline & Negative regulation of transcription & 16481 & $3.1251 \times 10^{-6}$ & $8.0002 \times 10^{-5}$ & 4 & 166 \\
\hline & Heterochromatin formation & 31507 & $3.7388 \times 10^{-5}$ & $2.9910 \times 10^{-4}$ & 3 & 92 \\
\hline & Chromatin silencing & 6342 & $3.7388 \times 10^{-5}$ & $2.9910 \times 10^{-4}$ & 3 & 92 \\
\hline & Gene silencing & 16458 & $5.4046 \times 10^{-5}$ & $3.8433 \times 10^{-4}$ & 3 & 104 \\
\hline & Chromatin modification & 16568 & $5.8205 \times 10^{-4}$ & $2.8655 \times 10^{-3}$ & 3 & 231 \\
\hline & Regulation of cell cycle & 74 & $7.1144 \times 10^{-3}$ & $1.5701 \times 10^{-2}$ & 2 & 160 \\
\hline \multirow[t]{2}{*}{ Cluster 8} & RNA biosynthetic process & 32774 & $2.4585 \times 10^{-3}$ & $1.8302 \times 10^{-2}$ & 2 & 289 \\
\hline & Transcription & 6350 & $1.0545 \times 10^{-2}$ & $4.8996 \times 10^{-2}$ & 2 & 598 \\
\hline \multirow[t]{7}{*}{ Cluster 9} & Intracellular $\mathrm{pH}$ reduction & 51452 & $4.8791 \times 10^{-5}$ & $6.6815 \times 10^{-4}$ & 2 & 24 \\
\hline & Vacuolar acidification & 7035 & $4.8791 \times 10^{-5}$ & $6.6815 \times 10^{-4}$ & 2 & 24 \\
\hline & Regulation of intracellular $\mathrm{pH}$ & 51453 & $5.3028 \times 10^{-5}$ & $6.6815 \times 10^{-4}$ & 2 & 25 \\
\hline & Proton transport & 15992 & $1.1756 \times 10^{-4}$ & $9.1538 \times 10^{-4}$ & 2 & 37 \\
\hline & Cellular homeostasis & 19725 & $2.1588 \times 10^{-3}$ & $6.8004 \times 10^{-3}$ & 2 & 158 \\
\hline & Ion transport & 6811 & $2.3248 \times 10^{-3}$ & $6.9745 \times 10^{-3}$ & 2 & 164 \\
\hline & ATP metabolic process & 46034 & $1.2324 \times 10^{-2}$ & $2.9858 \times 10^{-2}$ & 1 & 24 \\
\hline
\end{tabular}


Table 4 Main specific gene ontology categories observed in clusters derived from union PPPI network (Continued)

\begin{tabular}{|c|c|c|c|c|c|c|}
\hline Cluster 10 & Histone methylation & 16571 & $1.2655 \times 10^{-9}$ & $1.0504 \times 10^{-7}$ & 5 & 17 \\
\hline & Regulation of transcription & 45449 & $5.8795 \times 10^{-8}$ & $2.0914 \times 10^{-6}$ & 12 & 631 \\
\hline & Post-translational protein modification & 43687 & $3.6875 \times 10^{-7}$ & $3.9921 \times 10^{-6}$ & 10 & 454 \\
\hline & Chromosome organization and biogenesis & 7001 & $1.7266 \times 10^{-5}$ & $9.3463 \times 10^{-5}$ & 8 & 398 \\
\hline & Regulation of conjugation with cellular fusion & 31137 & $4.4395 \times 10^{-3}$ & $1.3481 \times 10^{-2}$ & 2 & 31 \\
\hline & Ethanol biosynthetic process during fermentation & 43458 & $6.5202 \times 10^{-3}$ & $1.7647 \times 10^{-2}$ & 1 & 2 \\
\hline & Response to stress & 6950 & $1.2590 \times 10^{-2}$ & $2.9574 \times 10^{-2}$ & 6 & 632 \\
\hline & Glycolytic fermentation & 19660 & $2.2645 \times 10^{-2}$ & $4.6218 \times 10^{-2}$ & 1 & 7 \\
\hline Cluster 11 & Chromosome organization and biogenesis & 7001 & $1.1865 \times 10^{-3}$ & $2.9377 \times 10^{-2}$ & 5 & 398 \\
\hline & DNA repair & 6281 & $1.2413 \times 10^{-3}$ & $2.9377 \times 10^{-2}$ & 4 & 228 \\
\hline & Mitotic cell cycle & 278 & $3.2147 \times 10^{-3}$ & $4.5671 \times 10^{-2}$ & 4 & 295 \\
\hline & Histone acetylation & 16573 & $3.4260 \times 10-3$ & $4.5671 \times 10^{-2}$ & 2 & 40 \\
\hline
\end{tabular}

${ }^{a} P$ values were calculated by the hypergeometric distribution of one ontology class visualized in the network.

${ }^{b}$ Calculated values based on $P$ values obtained after FDR was applied.

' Total number of proteins found in the network which belong to a gene ontology.

${ }^{d}$ Total number of proteins that belong to a specific gene ontology.

\section{Conclusions}

Propolis is a complex product derived from plant resins and bee's saliva. There are several chemical compounds present in this natural product that could potentially be responsible for its antibiotic properties. However, taking

Table 5 Selected bottleneck nodes observed in the union PPPI network

\begin{tabular}{ll}
\hline $\begin{array}{l}\text { Bottleneck nodes of genes that were } \\
\text { found as induced in microarray* }\end{array}$ & $\begin{array}{l}\text { Bottleneck nodes of } \\
\text { genes that were found } \\
\text { as repressed on microarray* }\end{array}$ \\
\hline TIM10 & BRN1 \\
\hline RLF2 & SMC4 \\
\hline VMA7 & RFM1 \\
\hline VMA21 & CEP3 \\
\hline ATP17 & MAM1 \\
\hline ATP18 & NSL1 \\
\hline ATP20 & SPC24 \\
\hline AZR1 & SLK19 \\
\hline PDR12 & ESA1 \\
\hline TPO1 & IFH1 \\
\hline TPO4 & HOS2 \\
\hline YOR1 & LEO1 \\
\hline DFM1 & SGF29 \\
\hline GRX4 & NGG1 \\
\hline TRX1 & IES2 \\
\hline TSA2 & \\
\hline GT12 & \\
\hline GT13 & \\
\hline PKR1 & \\
\hline ENA2 & \\
\hline SOP4 & \\
\hline Indiatesente & \\
\hline
\end{tabular}

* Indicates genes that were significantly up- or down-regulated in the microarray analysis. into consideration the fact that the cell death effects of propolis could be due to a great combination of chemical compounds and concentrations, we decided to investigate the cell death effects of propolis by concentrating our experiments on alcoholic extracts of propolis In summary, our data indicate that propolis is largely affecting several pathways in the eukaryotic cell. However, the most prominent pathways are related to oxidative stress, mitochondrial electron transport chain, vacuolar acidification, regulation of macroautophagy associated with protein target to vacuole, cellular response to starvation, and negative regulation of transcription from RNA polymerase II promoter. Our work emphasizes again the importance of $S$. cerevisiae as a model system to understand at molecular level the mechanism whereby propolis causes cell death in this organism at the concentration herein tested. Our study is the first one that investigates systematically by using functional genomics how propolis influences and modulates the mRNA abundance of an organism and may stimulate further work on the propolis-mediated cell death mechanisms in fungi.

\section{Additional files}

Additional file 1: Table A1. Genes with increased or repressed mRNA expression and grouped according to the GO identity.

Additional file 2: Table A2. Induced- and repressed- genes associated PPPI networks.

Additional file 3: Table A2. Sub networks present in the union PPPI network and their $\mathrm{GO}$ analysis.

Additional file 4: Table A4. Centrality analysis.

The authors declare that they have no competing interests. 


\section{Authors' contributions}

PAC and MS performed most of the experiments. PAC, DB, AB, IM, MHSG and GHG performed data analysis. GHG wrote the manuscript; conceived, designed and coordinated this study; and is the principal investigator of this work. All authors read and approved final manuscript

\section{Acknowledgements}

This research was supported by the Fundação de Amparo à Pesquisa do Estado de São Paulo (FAPESP), and Conselho Nacional de Desenvolvimento Científico e Tecnológico (CNPq), and Financiadora de Estudos e Projetos (FINEP), Brazil.

\section{Author details}

${ }^{1}$ Faculdade de Ciências Farmacêuticas de Ribeirão, Preto Universidade de São Paulo, São Paulo, Brazil. ${ }^{2}$ Centro de Biotecnologia da UFRGS, Universidade Federal do Rio Grande do Sul, Porto Alegre, Brazil. ${ }^{3}$ Departamento de Genética e Evolução, Centro de Ciências Biológicas e da Saúde (CCBS), Universidade Federal de São Carlos, Porto Alegre, Brazil. ${ }^{4}$ Faculdade de Filosofia, Ciências e Letras de Ribeirão Preto, Universidade de São Paulo, São Paulo, Brazil. ${ }^{5}$ Apis Flora Industrial e Comercial, Ribeirão Preto, São Paulo, Brazil. '́Laboratório Nacional de Ciência e Tecnologia do Bioetanol - CTBE, Caixa Postal 6170, Campinas, São Paulo 13083-970, Brazil.

Received: 31 July 2012 Accepted: 17 October 2012

Published: 24 October 2012

\section{References}

1. Ghisalberti EL: Propolis: a review. Bee World 1979, 60:59-84.

2. Greenaway W, Scaysbrook T, Whatley FR: The composition and plant origins of propolis. Bee World 1990, 71:107-118.

3. Viuda-Martos M, Ruiz-Navajas Y, Fernandez-Lopez J, Perez A, Alvarez AJ: Functional properties of honey, propolis, and royal jelly. J Food Sci 2008, 73:R117-R124.

4. Matsuno T, Matsumoto Y, Saito N, Morikawa J: Isolation and characterization of cytotoxic diterpenoid isomers from propolis. Z Naturforsch 1997, C 52:702-704.

5. Vynograd N, Vynograd I, Sosnowski Z: A comparative multicenterstudy of the efficacy of propolis, acyclovir and placebo in the treatment of genital herpes (HSV). Phytomedicine 2000, 7:1-6.

6. Kimoto T, Arai S, Kohguchi M, Nomura Y, Micallef MJ, Kurimoto M, Mito K: Apoptosis and suppression of tumor growth by artepillin C extracted from Brazilian propolis. Cancer Detect Prev 1998, 22:506-515.

7. Cigut T, Polak T, Gasperlin L, Raspor P, Jamnik P: Antopxidative activity of propolis extract in yeast cells. J Agric Food Chem 2011, 9:11449-11455.

8. Koru O, Toksoy F, Acikel CH, Tunca YM, Baysallar M, Uskudar Guclu A, Akca E, Ozkok Tuylu A, Sorkun K, Tanyuksel M, Salih B: Oral and dental bacteriology and infection. In vitro antimicrobial activity of propolis samples from different geographical origins against certain oral pathogens. Anaerobe 2007, 13:140-145.

9. Park YK, Fukuda I, Ashida H, Nishiumi S, Yoshida K, Daugsch A, Sato HH, Pastore GM: Suppressive effects of ethanolic extracts from propolis and its main botanical origin on dioxin toxicity. J Agric Food Chem 2005, 53:10306-10309.

10. Menna-Barreto RF, Salomão K, Dantas AP, Santa-Rita RM, Soares MJ, Barbosa HS, de Castro SL: Different cell death pathways induced by drugs in Trypanosoma cruzi: an ultrastructural study. Micron 2009, 40:157-168.

11. Ito J, Chang FR, Wang HK, Park YK, Ikegaki M, Kilgore N, Lee KH: Anti-AIDS agents. 48.(1) Anti-HIV activity of moronic acid derivatives and the new melliforone-related triterpenoid isolated from Brazilian propolis. J Nat Prod 2001, 64:1278-1281.

12. Agüero MB, Gonzalez M, Lima B, Svetaz L, Sánchez M, Zacchino S, Feresin GE, Schmeda-Hirschmann G, Palermo J, Wunderlin D, Tapia A: Argentinean propolis from Zuccagnia punctata Cav. (Caesalpinieae) exudates: phytochemical characterization and antifungal activity. J Agric Food Chem 2010, 58:194-201.

13. Dalben-Dota KF, Faria MG, Bruschi ML, Pelloso SM, Lopes-Consolaro ME Svidzinski Tl: Antifungal activity of propolis extract against yeasts isolated from vaginal exudates. J Altern Complement Med 2010, 16:285-290.

14. Osiewacz HD, Scheckhuber CQ: Impact of ROS on ageing of two fungal model systems: Saccharomyces cerevisiae and Podospora anserina. Free Radic Res 2006, 40:1350-1358.
15. Salomão K, Pereira PR, Campos LC, Borba CM, Cabello PH, Marcucci MC, de Castro SL: Brazilian propolis: correlation between chemical composition and antimicrobial activity. Evid Based Complement Alternat Med 2008, 5:317-324.

16. Siqueira AB, Gomes BS, Cambuim I, Maia R, Abreu S, Souza-Motta CM, de Queiroz LA, Porto AL: Trichophyton species susceptibility to green and red propolis from Brazil. Lett Appl Microbiol 2009, 48:90-96.

17. de Castro PA, Savoldi M, Bonatto D, Barros MH, Goldman MH, Berretta AA, Goldman GH: Molecular characterization of propolis-induced cell death in Saccharomyces cerevisiae. Eukaryot Cell 2011, 10(3):398-411.

18. Brachmann CB, Davies A, Cost GJ, Caputo E, Li J, Hieter P, Boeke JD: Designer deletion strains derived from Saccharomyces cerevisiae S288C: a useful set of strains and plasmids for PCR mediated gene disruption and other applications. Yeast 1998, 14:115-132.

19. Semighini CP, Marins M, Goldman MHS, Goldman GH: Quantitative analysis of the relative transcript levels of $A B C$ transporter Atr genes in Aspergillus nidulans by real-time reverse transcription-PCR assay. Appl Environ Microbiol 2002, 68:1351-1357.

20. Shannon P, Markiel A, Ozier O, Baliga NS, Wang JT, Ramage D, Amin N Schwikowski B, Ideker T: Cytoscape: a software environment for integrated models of biomolecular interaction networks. Genome Res 2003, 13:2498-2504.

21. Bader GD, Hogue CW: An automated method for finding molecular complexes in large protein interaction networks. BMC Bioinformatics 2003, 4:2.

22. Scardoni G, Petterlini M, Laudanna C: Analyzing biological network parameters with CentiScaPe. Bioinformatics 2009, 25:2857-2859.

23. Maere S, Heymans K, Kuiper M: BiNGO: a Cytoscape plugin to assess overrepresentation of gene ontology categories in biological networks. Bioinformatics 2005, 21:3448-3449.

24. Rivals I, Personnaz L, Taing L, Potier M-C: Enrichment or depletion of a GO category within a class of genes: which test? Bioinformatics 2007, 23:401-407.

25. Benjamini Y, Hochberg Y: Controlling the False Discovery Rate: A Practical and Powerful Approach to Multiple Testing. J R Stat Soc Series B Stat Methodol 1995, 57:289-300

26. Gruber JV, Holtz R: Examining the genomic influence of skin antioxidants in vitro. Mediators Inflamm 2010, pii:230450.

27. Ernst R, Kueppers P, Stindt J, Kuchler K, Schmitt L: Multidrug efflux pumps: substrate selection in ATP-binding cassette multidrug efflux pumps-first come, first served? FEBS J 2010, 277(3):540-549.

28. Shahi P, Moye-Rowley WS: Coordinate control of lipid composition and drug transport activities is required for normal multidrug resistance in fungi. Biochim Biophys Acta 2009, 1794(5):852-859.

29. Sá-Correia I, dos Santos SC, Teixeira MC, Cabrito TR, Mira NP: Drug:H+ antiporters in chemical stress response in yeast. Trends Microbiol 2009, 17(1):22-31.

30. Sipos G, Kuchler K: Fungal ATP-binding cassette (ABC) transporters in drug resistance \& detoxification. Curr Drug Targets 2006, 7(4):471-481.

31. Ariño J, Ramos J, Sychrová H: Alkali metal cation transport and homeostasis in yeasts. Microbiol Mol Biol 2010, 74:95-120.

32. Inoue $Y$, Klionsky DJ: Regulation of macroautophagy in Saccharomyces cerevisiae. Semin Cell Dev Biol 2010, 21:664-670.

33. Lynch-Day MA, Klionsky DJ: The Cvt pathway as a model for selective autophagy. FEBS Lett 2010, 584:1359-1366.

34. Schauer A, Knauer H, Ruckenstuhl C, Fussi H, Durchschlag M, Potocnik U, Fröhlich K-U: Vacuolar functions determine the mode of cell death. Biochim Biophys Acta 2009, 1793:540-545.

35. Eisenberg $T$, Knauer $H$, Schauer A, Büttner S, Ruckenstuhl C, CarmonaGutierrez D, Ring J, Schroeder S, Magnes C, Antonacci L, Fussi H, Deszcz L, Hartl R, Schraml E, Criollo A, Megalou E, Weiskopf D, Laun P, Heeren G, Breitenbach M, Grubeck-Loebenstein B, Herker E, Fahrenkrog B, Fröhlich KU, Sinner F, Tavernarakis N, Minois N, Kroemer G, Madeo F: Induction of autophagy by spermidine promotes longevity. Nat Cell Biol 2009, 11:1305-1314.

36. Ota C, Unterkircher C, Fantinato V, Shimizu MT: Antifungal activity of propolis on different species of Candida. Mycoses 2001, 44:375-378.

37. Perrone GG, Tan SX, Dawes IW: Reactive oxygen species and yeast apoptosis. Biochim Biophys Acta 2008, 1783:1354-1368.

38. Eisenberg T, Carmona-Gutierrez D, Büttner S, Tavernarakis N, Madeo F: Necrosis in yeast. Apoptosis 2010, 15:257-268. 
39. Odat O, Matta S, Khalil H, Kampranis SC, Pfau R, Tsichlis PN, Makris AM: Old yellow enzymes, highly homologous FMN oxidoreductases with modulating roles in oxidative stress and programmed cell death in yeast. J Biol Chem 2007, 282:36010-3623.

40. Teste MA, Duquenne M, François JM, Parrou JL: Validation of reference genes for quantitative expression analysis by real-time RT-PCR in Saccharomyces cerevisiae. BMC Mol Biol 2009, 10:99.

41. Borgatti SP: Centrality and network flow. Soc Networks 2005, 27:55-71.

42. Estrada E: Virtual identification of essential proteins within the protein interaction network of yeast. Proteomics 2006, 6:35-40.

43. Estrada E, Hatano NA: Vibrational approach to node centrality and vulnerability in complex networks. Phys A 2010, 389:3648-3660.

44. Newman MEJ: A measure of betweenness centrality based on random walks. Soc Networks 2005, 27:39-54.

45. Girvan M, Newman ME: Community structure in social and biological networks. Proc Natl Acad Sci USA 2002, 99:7821-7826.

46. Yu H, Kim PM, Sprecher E, Trifonov V, Gerstein M: The importance of bottlenecks in protein networks: correlation with gene essentiality and expression dynamics. PLoS Comput Biol 2007, 3:e59.

doi:10.1186/1472-6882-12-194

Cite this article as: de Castro et al:: Transcriptional profiling of

Saccharomyces cerevisiae exposed to propolis. BMC Complementary and Alternative Medicine 2012 12:194.

\section{Submit your next manuscript to BioMed Central and take full advantage of:}

- Convenient online submission

- Thorough peer review

- No space constraints or color figure charges

- Immediate publication on acceptance

- Inclusion in PubMed, CAS, Scopus and Google Scholar

- Research which is freely available for redistribution 